
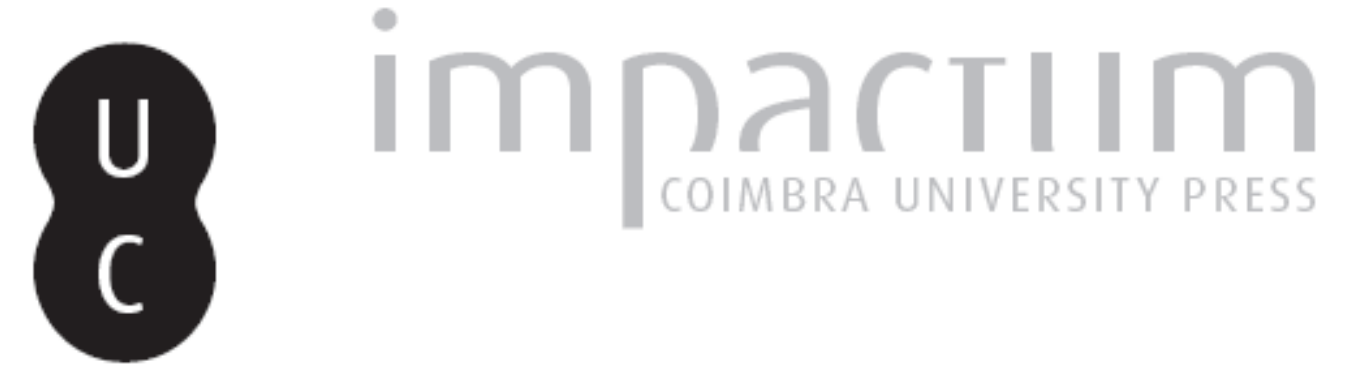

\title{
Quando a Revolução de Abril atropelou Itália: a suspensão do Partido da Democracia Cristã e as repercussões no XIV Congresso do Partido Comunista Italiano
}

Autor(es): $\quad$ Gomes, Marco

Publicado por: Imprensa da Universidade de Coimbra

URL persistente:

URI:http://hdl.handle.net/10316.2/36434

DOI:

DOI:http://dx.doi.org/10.14195/1647-8622_10_8

Accessed : $\quad$ 26-Apr-2023 14:13:27

A navegação consulta e descarregamento dos títulos inseridos nas Bibliotecas Digitais UC Digitalis, UC Pombalina e UC Impactum, pressupõem a aceitação plena e sem reservas dos Termos e Condições de Uso destas Bibliotecas Digitais, disponíveis em https://digitalis.uc.pt/pt-pt/termos.

Conforme exposto nos referidos Termos e Condições de Uso, o descarregamento de títulos de acesso restrito requer uma licença válida de autorização devendo o utilizador aceder ao(s) documento(s) a partir de um endereço de IP da instituição detentora da supramencionada licença.

Ao utilizador é apenas permitido o descarregamento para uso pessoal, pelo que o emprego do(s) título(s) descarregado(s) para outro fim, designadamente comercial, carece de autorização do respetivo autor ou editor da obra.

Na medida em que todas as obras da UC Digitalis se encontram protegidas pelo Código do Direito de Autor e Direitos Conexos e demais legislação aplicável, toda a cópia, parcial ou total, deste documento, nos casos em que é legalmente admitida, deverá conter ou fazer-se acompanhar por este aviso.

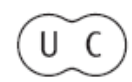




\section{crises do século}

\section{ESTUD OSD OSÉCULO}

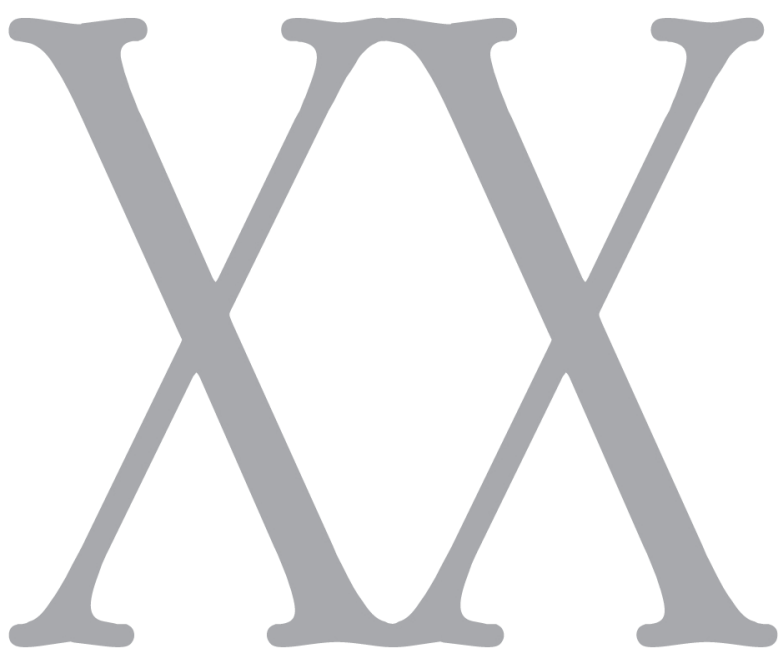

número $10 \cdot 2010$

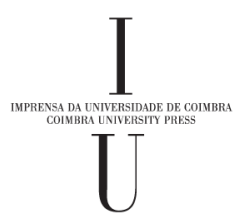




\title{
Quando a Revolução de Abril atropelou Itália
} a suspensão do Partido da Democracia Cristã e as repercussões no XIV Congresso do Partido Comunista Italiano

\author{
Marco Gomes
}


Marco Gomes, Mestre em História das Ideologias e Utopias Contemporâneas, pela Faculdade de Letras da Universidade de Coimbra, bolseiro de doutoramento da Fundação para a Ciência e Tecnologia, Colaborador do CEIS20. E-mail: gomes_marco78@hotmail. com. 
«Portugal pesa sobre o congresso do PCI depois do clamoroso retiro da delegação DC» ${ }^{1}$. Eis a manchete que fazia a primeira página do Corriere della Sera, a 20 de Março de 1975. No mesmo dia, o título central da Stampa confirmava o fragor que os acontecimentos portugueses causavam na política interna italiana: «Polémica sobre os factos de Lisboa depois do retiro dos delegados $\mathrm{DC}{ }^{2}$.

Desde o início de 1975 que a Revolução do 25 de Abril cimentava, progressivamente, o seu carácter excepcional no âmbito da imprensa transalpina. O golpe falhado do dia 11 de Março acelerara este perene movimento de factos e, sobretudo, exegeses. E motivou, em consequência, o avanço do processo revolucionário lusitano, com as nacionalizaçóes da banca $^{3}$, dos seguros, e a suspensão da actividade política de três partidos, entre os quais o Partido da Democracia Cristã (PDC), determinando a exclusão das eleiçóes do dia 25 de Abril de $1975^{4}$.

A interdição do PDC avolumou a desconfiança dos partidos italianos relativamente à natureza democrática do regime português. A inquietude adquiriu singulares dimensóes muito por força do timing de ocorrência. No dia 18 de Março, altura em que se tornava público o afastamento dos correligionários do major Sanches Osório, tinha início o XIV Congresso do Partido Comunista Italiano (PCI).

A reunião destinada a avaliar as possibilidades do compromisso histórico desenrolou-se sob o espectro das ocorrências de Lisboa. E ficou marcada pelo abandono dos delegados da Democracia Cristã italiana em sinal de protesto pela decisão do Conselho da Revoluçáo. O turbilhão extravasou fronteiras, como descreve o editorial do France-Soir: ${ }^{5}$

"Os acontecimentos de Portugal estáo já modificando as perspectivas políticas da esquerda europeia. O problema é particularmente grave em Itália. Enrico Berlinguer empenhou-se com determinaçáo num novo caminho. [...] Agora, depois dos factos de Lisboa, este "compromisso" parece seriamente em perigo".

Efectivamente, a Rivoluzione dei Garofani agitou intensamente a opinião pública mundial e (re)lançou, através de fitos analógicos, as mais variegadas problemáticas. Se o "caso República» produziu um inusitado vendaval nos meios políticos e intelectuais francesas, contrapondo concepçóes díspares de conceitos como a liberdade de expressão e liberdade de imprensa, semelhantes réplicas chegaram ao país de Garibaldi. A pergunta dove va il Portogallo? suscitou inflamadas discussóes, sessóes no parlamento, preferências políticas em detrimento de opçóes editoriais e apaixonou a esquerda extra-parlamentar.

\footnotetext{
${ }^{1}$ BIANCHI, Luigi - «Il Portogallo pesa sul congresso del PCI dopo il clamoroso ritiro della delegazione dc». Corriere della Sera. Milano: Edit. Corriere della Sera. Ano 100, No 65 (20 Mar. 1975) capa.

${ }^{2}$ «Polemiche sui fatti di Lisbona dopo il ritiro dei delegati dc». La Stampa. Torino: Edit. La Stampa. Ano 109, No 64 (20 Mar. 1975) capa.

${ }^{3}$ A operação provocou a estatização dos jornais $O$ Século (e publicaçóes associadas), Diário Popular, O Jornal do Comércio, O Comércio do Porto, A Capital e o Diário de Lisboa (parcial).

${ }^{4}$ O Movimento Reorganizativo do Partido do Proletariado e a Aliança Operária Camponesa foram também suspensos. Na origem da interdição esteve a acusação de incitamento e recurso à violência. No caso do PDC, foi ainda imputado o envolvimento de alguns líderes no 11 de Março.

5 "Chiesto un dibattito sul Portogallo", cit. por Corriere della Sera. Ano 100, No 66 (21 Mar. 1975) p. 2.
} 
O XIV Congresso do PCI, que decorreu entre 18 e 23 de Março de 1975, esteve rodeado de fundadas expectativas aos olhos da opiniáo pública. De acordo com a previsibilidade do evento, os jornais diários conferiram-lhe um tratamento, simultaneamente, factual/informativo e interpretativo/comentado. Durante seis dias transformou-se na questão nuclear ao nível da política interna.

Este artigo pretende responder a duas questóes: Em que medida a exclusão do Partido da Democracia Cristã das eleiçóes para a Assembleia Constituinte influenciou os trabalhos do XIV Congresso do PCI? Qual o tratamento jornalístico concedido à conferência? A pesquisa privilegia as ediçóes dos jornais Corriere della Sera, La Stampa e Il Messaggero ${ }^{6}$. Procurámos elementos explicativos no sentido de determinar quais os actores evocados e os cenários políticos desenhados. Náo esquecendo alguns dados quantitativos que contribuem para reforçar a «ressonância» do evento.

A escolha da imprensa escrita - de referência - radica na centralidade que este instrumento, em plena década de 70 do século XX, assumia para a classe política, como elemento para informar e manter informado, para gerar e consumir ideologia.

\section{Imprensa de referência: a instituição, o prestígio, e a vocação política}

Paolo Murialdi ${ }^{7}$ salientava, em 1976, a crítica mais difusa ao jornalismo político italiano: a notícia e a opinião misturam-se no mesmo texto, formam o clássico pastone. Umberto $\mathrm{Eco}^{8}$, por sua vez, afirmava-se bem mais contundente:

«O jornal [italiano] desenvolve o seu objectivo político de boletim de opinião e troca de informaçóes e pressóes entre grupos de poder [...]. O quotidiano não aparece como um instrumento de liberalizaçáo crítica [...], mas como um instrumento autoritário de repressão».

Apesar dos reparos à praxis e cultura do jornalismo da península, Corriere della Sera e La Stampa apresentam uma vigorosa casta que lhes confere um lugar de referência no plano internacional. Em 1975 lideravam a média de exemplares vendidos em Itália, na ordem dos 500.400 e $361.100^{9}$, respectivamente. São os mais relevantes quotidianos nacionais. Autores como Paolo Murialdi, Nicola Tranfaglia e Mario Grandinetti ${ }^{10}$ colocam também o Messaggero entre os jornais italianos de primeira linha, sendo considerado um diário inter-regional. Com 227.500 unidades médias ocupava o quarto posto, depois de l'Unità.

\footnotetext{
${ }^{6}$ Analisámos 23 ediçóes, entre 18 e 25 de Março de 1975. A amostra do diário La Stampa apresenta menos uma edição porque não saía à segunda-feira.

${ }^{7}$ MURIALDI, Paolo - Come si legge un giornale. 6a edição. Roma: Laterza, 1976, p. 47.

${ }^{8}$ Cit. por BECHELLONI, Giovanni - Informazione e potere: la stampa quotidiana in Itália. Roma: Officina, 1974, p. 94.

${ }^{9}$ MURIALDI, Paolo - Storia del giornalismo italiano. $2^{a}$ ediçăo. Bologna: Il Mulino, 2006. ISBN: 9788815112989, p. 243.

${ }^{10}$ CASTRONOVO, Valerio; TRANFAGLIA, Nicola (coord.) - La stampa italiana nelle'età della TV. Dagli anni settanta a oggi. 3a ediçáo. Bari: Laterza, 2008. ISBN: 97888420855844, p. 5-63.
} 
Seguindo a definição de Mário Mesquita ${ }^{11}$, a imprensa de referência abarca os periódicos direccionados, preferencialmente, para "a "opiniâo pública dirigente" (associada à tomada de decisóes ao nível político, económico e cultural)». Jornais de elite ou qualidade é outra terminologia que entronca nesta categoria.

Podemos então classificar o Corriere della Sera, La Stampa e Il Messaggero como sendo diários matutinos, de informação, de qualidade ou elite. O Corriere correspondia ao tradicional órgão da burguesia lombarda. Moderado, preconizador de uma linha elitista ao nível político, cultural e editorial, foi durante muito tempo o sustentáculo da Democracia Cristã (DC).

O quotidiano da Via Solferino era sinónimo de jornalismo de qualidade, respeito, costumes, o mais difuso e presença mítica no seio da categoria profissional. Imagem, no entanto, abalada, nos anos 80 , pela ascensão meteórica do Repubblica ${ }^{12}$ e pelo envolvimento de alguns jornalistas no escândalo da loja maçónica Propaganda Dois. Como refere Marino Livolsi ${ }^{13}$, por 80 anos, não se tratou tanto do maior jornal italiano, mas sim «o jornal italiano». O modelo e referência. A instituição.

Mais a sudoeste, em Torino, está instalado o arqui-rival La Stampa, dos Agnelli e da Fiat. Cultivou sempre uma postura bicéfala entre a vocaçáo regional, citadina, e a disposição nacional e internacional. Esta última consolidada e impulsionada pelo histórico director Giulio De Benedetti, conferindo uma indelével marca de prestígio.

É um jornal liberal, laico e democrático. Acompanhou as tendências da sociedade, do (neo)centrismo ao centro-esquerda, adepto do reformismo e do projecto europeu. A imagem de inovação tecnológica, pioneira entre os concorrentes, contribuiu para conservar o segundo posto de vendas. Apenas destronado pelo ciclone de Eugenio Scalfari. De assinalar a relação construtiva que envolveu administradores, redactores e tipógrafos, permitindo, depois de acesos conflitos, ultrapassar os negros anos 70 .

Aliás, a devastadora década de 70 italiana mergulhou os quotidianos numa grave crise financeira e em complexas equaçôes políticas, além do terrorismo. $\mathrm{O}$ tranquilo Messaggero haveria de ser afectado. De tendência conformista, tradicionalmente sensível ao posicionamento dos políticos e burocratas da capital, anticomunista, o mais importante e difuso órgão de Roma caracterizou-se pela oficialidade e, sobretudo, vocação política. O equilíbrio entre as linhas clerical e laica completava o seu código genético. Uma cidadela que não resistiu ao capital.

Do autunno caldo sopraram ventos rebeldes e, no triénio 73-75, o diário da família Perrone foi adquirido, faseadamente, por Eugenio Cefis ${ }^{14}$. Iniciava-se uma clamorosa disputa pelo controlo do jornal, originando greves, recursos a tribunais e importantes mudanças na linha editorial. Primeiro Alessandro Perrone, e depois Italo Pietra e Luigi Fossati, imprimiram uma orientação favorável ao Partido Socialista. Il Messaggero assumiu, neste turbulento momento, «tons extremistas», quase de barricada, e adoptou

\footnotetext{
${ }^{11}$ MESQUITA, Mário; REBELO, José - O 25 de Abril nos média internacionais, ob. cit. Porto: Afrontamento, 1994. ISBN: 9723603284, p. 15.

${ }^{12} \mathrm{O}$ jornal dirigido por Eugenio Scalfari nasceu em Janeiro de 1976.

${ }^{13}$ LIVOLSI, Marino - La fabbrica delle notizie. Milano: Franco Angeli Libri, 1984, p. 46.

${ }^{14}$ Empresário próximo da DC. Financiou, directa ou indirectamente, várias publicaçôes, entre as quais o Corriere della Sera.
} 
o modelo de assembleia como prática de gestão ${ }^{15}$. Subitamente, passou ao radicalismo laico e libertário, antidemocrata-cristão.

\section{O compromisso histórico}

A XIV reunião magna do PCI inseriu-se na tendência que Aberto Cecchi ${ }^{16}$ situa a partir de 1945: transformar uma assembleia de partido, os problemas políticos italianos, num debate mais amplo. Em 1975, foram convidados, pela primeira vez, os diplomatas das 95 embaixadas presentes em Roma. Aproximaram-se de uma centena as delegaçóes estrangeiras, entre partidos comunistas, socialistas e sociais-democratas.

Deste panorama emergia a intenção de fornecer uma imagem internacional do PCI em conformidade com a linha do compromisso histórico, a temática central do evento. Em 28 de Setembro de 1973, Enrico Berlinguer ${ }^{17}$ iniciava uma série de três artigos, na Rinascita, através dos quais proponha uma nova aliança entre as forças que representavam «a grande maioria do povo italiano», do proletariado aos camponeses, dos católicos aos laicos. Um propósito extraído da unidade popular e democrática que Palmiro Togliatti apregoara.

$\mathrm{Na}$ origem da proposta residiam motivaçóes nacionais, reformadoras. O secretário comunista estava persuadido da impossibilidade de governar unicamente com as forças de esquerda, comunistas e socialistas. Mesmo que contassem com $51 \%$ dos votos. Pretendia, por isso, uma renovada coligação com a DC, que contava três décadas de governo. Não excluindo o Partido Socialista (PSI). Urgia proporcionar «à naçáo um caminho seguro de desenvolvimento económico, de renovamento social e de progresso democrático».

O projecto repercutia ainda a atmosfera internacional. A queda de Salvatore Allende iluminou os temores - já bem presentes - quanto a acçóes reaccionárias. A partir de 1969, o fantasma fascista adquiriu expressão quando, em resposta aos movimentos estudantil e operário, se foi afirmando a estratégia de tensão, impulsionada pela mobilização da extrema-direita. Como refere Paul Ginsborg, as forças reaccionárias «procuravam criar um "clima de desesperada tensão" que abrisse o caminho a um governo autoritário ou pelo menos uma durável permanência de direita» ${ }^{18}$.

A derrota no referendo do divórcio ${ }^{19}$, em 1974, fragilizou os equilíbrios da DC. Sinal de que a mundividência individual sobrepusera-se aos vínculos políticos. Estava em marcha o processo de secularização e a ruptura do imaginário colectivo. Assistiu-se à explosão de formas de luta inéditas, de novas identidades, do movimento feminista à contestação estudantil e grupos autónomos. Fermentos que fracturaram atavismos e revolucionaram a linguagem, os comportamentos e valores, das relaçóes sexuais ao conceito de família cristã. Aquilo que Vittorio Vidotto define como representação ideológica da sociedade italiana ${ }^{20}$.

1515 Storia del giornalismo..., ob. cit., p. 245.

${ }^{16}$ CECCHI, Alberto - Storia del P.C.I. attraverso i congressi. Roma: Newton Compton, 1975, p. 8.

${ }^{17}$ BERLINGUER, Enrico - «Alleanze sociali e schieramenti politici». Rinascita. Roma: Rinascita. Ano 30, N.o 40 (12 Out. 1973) p. 12.

${ }^{18}$ GINSBORG, Paul - Storia d'Italia dal dopoguerra a oggi: società e politica 1943 - 1988, ob. cit. Torino: Einaudi, 1989. ISBN: 880611879X, p. 479.

${ }^{19}$ Foi promovido pela DC no sentido de inserir mais restriçóes na lei que regulava o divórcio.

${ }^{20}$ VIDOTTO, Vittorio - «La Nuova Societá». In BATTISTA, Pierluigi - L'Italia Contemporanea: dal 1963 a oggi. Roma: Laterza, 1999. ISBN: 8842058548. Volume VI, p. 71. 
A partir do milagre económico (1955-1965) crescera a perspectiva hedonista e do consumo individual. Pier Paolo Pasolini ${ }^{21}$ aludiu à metamorfose social evocando o fenómeno do "desaparecimento dos pirilampos». No famigerado artigo do Corriere della Sera relacionava o eclipse dos pirilampos, típicos dos campos e terrenos agrícolas, com a extinção dos valores tradicionais: "pátria, família, obediência, ordem, poupança, moralidade». Pasolini afirmava que o "poder dos consumos» havia "deformado a consciência do povo italiano até à irreversível destruição».

Entre 1968 e 1980 eclodiu uma torrente fenomenológica dramática: execração do terrorismo, de extrema-direita, extrema-esquerda e de Estado; lutas operárias; profunda crise do sistema político e das instituiçóes, do financiamento ilícito à corrupção, formas de organização e representatividade, escândalos, práticas clientelares e transformistas; maior crise económica do pós-segunda guerra; fragmentação da unidade católica.

O compromisso histórico pretendia defender uma democracia ameaçada, fazer face ao radicalismo críptico. Uma democracia que enfrentava, mais do que elementos avulsos, o espectro da conflitualidade permanente. O assassinato de Aldo Moro, em 1978, constitui o episódio símbolo desta onda insurreccional.

\section{Entre expectativas e ambiguidades}

O debate pré-congressual iniciou-se em Dezembro de 1974, quando Berlinguer apresentou A Proposta Comunista. E logo no mês seguinte a Rinascita inaugurou um espaço de discussão, a Tribuna congressuale. L'Unità, o outro órgáo oficial do partido, secundava a iniciativa da revista semanal.

A exposição de ideias abarcou os principais órgãos de comunicação. Portugal foi sempre uma referência constante: Qual o papel do Movimento das Forças Armadas na vida política? O que prevalecerá: o voto ou o veto? Sem esquecer a lei da unidade sindical, assunto que opôs Mário Soares e Álvaro Cunhal a partir de Janeiro de 1975, também na ordem do dia em Itália

Quando os congressistas afluíram, a 18 de Março, ao Palácio do Desporto, em Roma, Il Messaggero ${ }^{22}$ sintetizava a análise dominante: "Jamais como neste momento a opinião pública observa o que existe de novo e de positivo no mais forte partido da oposição. O XIV Congresso [...] acontece num momento particularmente difícil para o país. O quadro político é instável».

A publicação romana fez valer a vocação política e concedeu, nesta fase de previsões, o maior destaque à conferência. Os géneros jornalísticos privilegiaram a interpretação, sob a forma de editorial e nota política. O serviço de Romano Dapas aludiu ${ }^{23}$ ao surgimento de "complicaçóes de ordem internacional» caso os comunistas se inserissem «na área do poder». Não bastavam as intençôes de Berlinguer em destacar-se do alinhamento soviético para anular o problema de «segurança internacional» e conferir

\footnotetext{
${ }^{21}$ PASOLINI, Pier Paolo - «Il vuoto del potere in Italia». Corriere della Sera. Ano 100, N. 26 (01 Fev. 1975) capa.

${ }^{22}$ DAPAS, Romano - «Cos'è il compromesso storico». Il Messaggero. Roma: Il Messaggero. Ano 97, N.o 73 (18 Mar. 1975) p. 2.

${ }^{23}$ Idem, ibidem.
} 
uma «imagem credível de um PCI autónomo nas suas opiniôes». Estavam em causa as relaçóes com os partidos comunistas orientais.

E o articulista continuou: «O que está acontecendo em Portugal encontra imediato eco no nosso país. Ao PCI oferece-se uma outra oportunidade para reafirmar a própria independência e rejeitar as instrumentalizaçóes que sobre os acontecimentos portugueses foram esboçadas pelos seus adversários».

O cenário internacional pulsava ao ritmo de graves incidentes: o golpe do 11 de Março e os acontecimentos decorrentes; a necessidade de preservar a Inglaterra na CEE e a revisão das condições financeiras de adesão; agravamento da situação bélica e humanitária no Vietname; a falência de Henry Kissinger no Medio Oriente.

"A "volta" de Berlinguer» ${ }^{24}$ fazia o título de outro esforço interpretativo, em primeira página, no jornal de Torino. Carlo Casalegno não tinha dúvidas em afirmar que, em redor do XIV Congresso, "existia uma expectativa demasiado dramática, quase podia determinar - para melhor ou para pior - uma volta histórica» na política italiana. Sublinhava a centralidade do acontecimento, "pelas propostas em discussão, pela força do partido [...], pelos reflexos internacionais», apesar do ingresso do PCI no governo não se afigurar um cenário concreto.

O vice-director identificava uma imagem «menos dogmática e combativa», até com «esboços de autocrítica». Referia que o compromisso histórico constituía «um facto político imediato». Mas o seu carácter ambíguo não esclarecia quais as linhas programáticas. Casalegno advertia para a incerteza de certas terminologias, como «movimentos populares», "elementos de socialismo», "superaçáo dos blocos militares». Asseverando: "Agora, Portugal está aprendendo».

A dubiedade quanto aos conteúdos do projecto de Berlinguer estava ainda presente na nota política de Luigi Bianchi ${ }^{25}$. O jornalista titulava, na capa do Corriere della Sera, a peça com um teor indicativo: «Abre-se hoje o congresso do PCI para discutir o "compromisso histórico"». Questionava a estratégia a seguir e a aliança com uma DC inflexível e pouco receptiva ao acordo.

Tal como os colegas da Stampa e do Messaggero, Bianchi assumia que as divergências entre as principais figuras comunistas adquiriam «contornos precisos». Se Giorgio Amendola afirmava: «Não há tempo a perder, o acordo deve ser feito antes que o barco afunde». Já Pietro Ingrao recusava uniôes com o tradicional modelo de desenvolvimento democrata-cristão. Importava "pressionar a DC até provocar internamente verdadeiras rupturas» ${ }^{26}$.

Amendola e Ingrao representavam dois pólos opostos dentro da linha estratégica. Umberto Terracini era céptico por princípio. O comentário político assegurava, porém, que a liderança não estava em discussão. Competia ao secretário-geral moderar posiçôes.

\footnotetext{
${ }^{24}$ CASALEGNO, Carlo - «La "svolta” di Berlinguer». La Stampa. Ano 109, N. 62 (18 Mar. 1975) capa.

${ }^{25}$ BIANCHI, Luigi - «Si apre oggi il congresso del PCI per discutere del "compromesso storico"». Corriere della Sera. Ano 100, N.o 63 (18 Mar. 1975) capa.

${ }^{26}$ Cit. por BIANCHI, Luigi - ibidem.
} 


\section{A intervenção de Berlinguer e as notícias de Lisboa}

Cerca de cinco mil pessoas escutaram, durante três horas, a comunicação inaugural de Berlinguer. Os três diários não manifestaram relevantes divergências ao nível da abordagem temática. Salientaram que o compromisso histórico destinava-se a impedir o «flagelo» económico e moral de Itália.

Reafirmando os princípios do internacionalismo proletário, o PCI afirmava-se em condiçôes para assumir o governo. Giovanni Trovati ${ }^{27}$, da Stampa, identificava uma nova linha na proposta comunista, em conformidade com «os vários organismos, do sindicato aos comités locais, conselhos de zona, e cooperativas».

Outro aspecto significante residia na importância que o pacto atlântico havia adquirido para Berlinguer, consciente das nefastas implicaçôes caso a Itália optasse por uma retirada unilateral. Ele que advogou uma Europa autónoma no xadrez internacional. E deu o exemplo da Jugoslávia.

Giovanni Trovati ${ }^{28}$ reconheceu duas preocupaçôes no pensamento do líder comunista: «Assegurar às outras forças políticas a autonomia da via nacional do PCI e a sua fidelidade à democracia, e confirmar às bases que o partido continua fiel aos princípios marxistas».

Mas permaneciam algumas dúvidas. E o cronista questionou: pode, numa sociedade socialista, o PCI «deixar o governo uma vez derrotado nas eleiçóes, e os outros partidos formarem uma diferente maioria? Ou a sociedade socialista exclui esta eventualidade?». Concretizando:

«Talvez teria ajudado a perceber melhor o seu pensamento se Berlinguer fosse mais esclarecedor sobre Portugal. [...] O objectivo de construir um regime efectivamente democrático não é fácil, mas em qualquer caso é claro que as condições de Itália são em tudo diferentes das de Portugal».

A escrita de Luigi Bianchi ${ }^{29}$ convergiu para apreciaçóes idênticas, destacando a serenidade da alocução, pouco dada a polémicas, «nem mesmo quando mencionou, brevemente, os acontecimentos portugueses». Berlinguer ${ }^{30}$ afirmara: «É um processo político complicado. Importa procurar compreender as dificuldades. Não é lícito, da parte de quem nunca levantou a voz contra a ditadura infame de Salazar e Caetano, propor hoje um julgamento presunçoso e hipócrita».

Se Andrei Kirilenko, o enviado do Kremlin, constituiu referência obrigatória, o dia de abertura foi todo de Berlinguer. A sessão inaugural fez as manchetes, a cinco colunas, dos quotidianos e ocupou, quase na totalidade, os espaços privilegiados da capa e segunda página. Dizemos quase porque, de facto, a reuniāo comunista teve de dividir, ao longo dos seis dias, o protagonismo com o tornado português.

\footnotetext{
${ }^{27}$ TROVATI, Giovanni - «Rassicurare la base e gli altri partiti». La Stampa. Ano 109, N.o 63 (19 Mar. 1975) capa.

${ }^{28}$ Idem, ibidem.

${ }^{29}$ BIANCHI, Luigi - «Compatibile con la NATO». Corriere della Sera. Ano 100, N.o 64 (19 Mar. 1975) p. 2.

${ }^{30}$ Cit. por BIANCHI, Luigi - ibidem.
} 
Corriere della Sera, La Stampa e Il Messaggero titulavam, sempre com destaque de primeira página, o efeito das invectivas militares. "Em Portugal excluídos das eleiçóes os democratas-cristãos e a extrema-esquerda ${ }^{31}$ : a decisão do Conselho da Revolução ${ }^{32}$ instituía o ponto de partida de uma ciclópica bola de neve que haveria de adquirir proporções invulgares.

La Stampa $a^{33}$ fez uma abordagem altamente crítica e inquietante. O comentário, não assinado, referia que "a arrogância do poder militar e o oportunismo ideológico dos comunistas portugueses» não conseguiam «mascarar o significado do decreto» do Conselho da Revolução (CR). Previa que os desenvolvimentos portugueses teriam «efeitos nos maiores países europeus [...], sobretudo nos dois grandes partidos comunistas ocidentais, o italiano e o francês, que por vias diversas mas paralelas anunciaram o seu caminho parlamentar e pluralista».

O enviado especial de Torino em Lisboa ${ }^{34}$ destacou o «forte impacto» da medida, «uma clamorosa ressonância em todo o ocidente». Classificou de «activismo febril» a acção do CR. Sandro Viola mencionava que a deliberação parecia destinada ao Centro Democrático Social (CDS), rotulando «o partido mais à direita de todo o alinhamento português». Uma visão não partilhada pelo enviado do Corriere ${ }^{35}$, que sentou os dois partidos na mesma cadeira de extrema-direita. Bernardo Valli aflorava ainda eventuais implicaçóes de Sanches Osório no 11 de Março.

Sandro Viola, recorrendo ao comentário político, relacionou o boicote com fins políticos estratégicos, sustentando que uma "campanha eleitoral conduzida com símbolos cristãos teria seguramente recuperado no "profundo norte" [...] a maioria dos consensos». Atribuía à influência do Partido Comunista Português (PCP) a exclusão das forças de extrema-esquerda.

As lentes dedutivas empurram, igualmente, o enviado romano para a feitura do pastone. Mas em sentido oposto. Sandro Osmani sublinhou que a directriz militar podia ser "considerada acima de tudo um formal atestado de "não democraticidade" dado aos democratas-cristãos». Escrevia que o procedimento permitia ao CR continuar «fiel ao princípio enunciado de conceder uma pluralidade democrática completa». Segundo o jornalista, o major Sanches Osório estava «implicado no golpe» e o CDS inspirava-se em princípios da Opus $\mathrm{Dei}^{36}$.

\section{Fanfani decreta a retirada do congresso}

A segunda jornada congressual assinalou uma inesperada alteração na ordem de trabalhos. "O PCI encontrou o caso de Portugal no momento em que menos queria. [...] A delegaçáo DC retirou-se do congresso comunista e a circunstância condicionou o debate, que do tema do "compromisso histórico" passou para a polémica aberta por

\footnotetext{
${ }^{31}$ VALLI, Bernardo - «In Portogallo esclusi dalle elezioni i democristiani e l'ultrasinistra», ibidem, capa.

${ }^{32}$ Decreto no $137-E / 75$, de 17 de Março.

33 "Non è più democrazia». La Stampa. Ano 109, N.o 63 (19 Mar. 1975) capa.

${ }^{34}$ VIOLA, Sandro - «Esclusi dalle prossime elezioni», ibidem.

35 «In Portogallo esclusi...», capa.

${ }^{36}$ OSMANI, Sandro - «Tre partiti al bando». Il Messaggero. Ano 97, N. 74 (19 Mar. 1975) p. 19.
} 
Fanfani», anotava a Stampa ${ }^{37}$. Na mesma linha avançava o Messaggero ${ }^{38}$ : «Não são apenas os acontecimentos portugueses a inspirar o debate político destes dias, mas também a sua coincidência com o congresso do PCI e a reacção da DC».

As ocorrências de Lisboa e, consequentemente, a retirada em protesto dos sequazes do secretário-geral da DC, Amintore Fanfani, por decisão deste, produziram encontros improvisados, comunicados, discursos redimensionados, conversas de bastidores e uma profusão de reacçôes surpreendente. A tempestade pulou fronteiras e conferiu dimensão à aldeia global de Marshall McLuhan.

As capas do Corriere della Sera, de 20 e 21 de Março, aproximam-se sobremaneira de páginas monográficas. Uma ideia que faz sentido associando os acontecimentos portugueses ao encontro do PCI. Porque, na realidade, a chave de leitura para interpretar o decurso do congresso requer a compreensão do que se passava na Península Ibérica. Os textos sobre Portugal fornecem informaçóes e comentários que ajudam a contextualizar as peças sobre a reunião comunista. E vice-versa.

Antonio Padellaro ${ }^{39}$ escrevia, no diário milanês, que «Fanfani decidiu jogar uma cartada de grande efeito». O líder da delegação democrata-cristã, Attillio Ruffini, deveria comunicar à cúpula comunista a opção pelo abando dos trabalhos. Mas a espera foi «inútil», declarou a organização do congresso.

Fanfani preferiu o Popolo para desenvolver a problemática, fazendo das capas - agora sim - dos dias 19 e 20 páginas totalmente monográficas. Segundo o órgão oficial da DC, os comunistas portugueses influenciaram a suspensão dos partidos para, juntamente com os militares, impor uma nova ditadura, porque temiam o "voto popular» ${ }^{40}$. Começava o aproveitamento das peripécias lusitanas que, entretanto, os expoentes da secretaria DC iriam alimentar para a agência noticiosa ANSA:

«A linha de todas as intervençóes [DC], mais do que exprimir, obviamente, uma severa condenação pelo abuso de força registado em Portugal e reforçar que a verdadeira face do comunismo continua sempre totalitária, deve confirmar em definitivo o fracasso do compromisso histórico» ${ }^{41}$.

As reacções oficiais do PCI não tardaram. Interrompendo espontaneamente a oratória matinal do dia 20, Allessandro $\mathrm{Natta}^{42}$ transmitiu a indignação da presidência do congresso, qualificando a acção da DC como um «pretexto para instrumentalizaçóes eleitorais e polemizar internamente factos de outros países». Um gesto «em tudo injustificado seja em relação à estratégia democrática do PCI seja às posiçóes assumidas sobre os complexos desenvolvimentos da situação portuguesa».

${ }^{37}$ TROVATI, Giovanni - «Portogallo e Italia», in La Stampa. Ano 109, N.o 64 (20 Mar. 1975) capa.

${ }^{38}$ DAPAS, Romano - «I commenti». Il Messaggero. Ano 97, N.o 75 (20 Mar. 1975) p. 2.

${ }^{39}$ PADELLARO, Antonio - «I drammatici dispacci da Lisbona». Corriere della Sera. Ano 100, N. 65 (20 Mar. 1975) capa.

${ }^{40}$ PINNA, Paolo - «I comunisti portoghesi temono il voto popolare». Il Popolo. Roma: Edit. Il Popolo. Ano 32, N. ${ }^{\circ} 64$ (20 Mar. 1975) capa.

${ }^{41}$ Cit. por PADELLARO, Antonio - «I drammatici dispacci...», capa.

${ }^{42}$ Cit. por BIANCHI, Luigi - «Il Portogallo pesa sul ...», capa. A Itália realizaria as eleiçôes Regionais em Junho de 1975. 
Mais do que um incidente institucional, a iniciativa de Fanfani representou um rude golpe nas aspiraçóes de Berlinguer, precisamente no momento em que lançava o apelo ao entendimento com a DC. Ou seja: o partido destinatário da terceira via não apenas se mostrava indisponível para perceber o fundamento do compromisso histórico, como recusava ouvir o que lhe era dirigido.

Os dirigentes comunistas clarificaram então a posição do partido diante da decisão do CR. A tarefa coube a Aldo Tortorella ${ }^{43}$, que definiu «bastante graves e sérios» os acontecimentos de Portugal. No entanto, importava "distinguir a análise de tal realidade da existência de uma situação em tudo excepcional», ainda marcada pelas "consequências de um golpe reaccionário». Reafirmou o «internacionalismo» e a «solidariedade com quem se esforça para construir uma sociedade nova».

Depois, sublinhando a plena autonomia do PCI, o director de l'Unità direccionou a animosidade para Fanfani: «Não nos identificamos com partidos que exaltamos o valor e que consideramos irmáos, seja porque entendemos a complexidade e diversidade das situaçóes históricas concretas, seja porque estamos tenazmente convictos das nossas ideias. Outra táctica segue a secretaria DC».

\section{A intensa espiral de reacçóes}

«A questão portuguesa», expressão que fez título no Messaggero ${ }^{44}$, causou profundo impacto na opinião pública italiana. Mobilizou movimentos sociais e políticos, de que são exemplo os incidentes verificados em Pistoia, na Toscana, entre estudantes democratas-cristáos e grupos de extrema-esquerda. $\mathrm{Ou}$ as divergências verificadas no Conselho Regional da mesma região, na sequência das posiçóes adoptadas por Guido Biondi (Partido de Unidade Proletária) em colisão com os companheiros de coligação, comunistas e socialistas.

Os responsáveis do Ministério dos Negócios Estrangeiros em Roma solicitaram a presença do embaixador português, Virgínio Martins, para melhor se inteirarem dos acontecimentos. A degradação das relaçóes entre partidos com responsabilidades políticas constituía um motivo de preocupação para o governo de Aldo Moro. Porque, na semana seguinte, estava agendada outra difícil ronda negocial no âmbito das questôes de ordem pública.

A disputa intelectual agigantou-se e os deputados da DC pediram um debate parlamentar. Flaminio Piccoli ${ }^{45}$ interpelou o governo italiano para que "encetasse oportunas iniciativas no sentido de restituir os termos de liberdade e de democracia que inspiraram o movimento de 25 de Abril de 1974». Requereu, portanto, a revogaçáo do decreto-lei. Uma pretensão que os dirigentes do PDC em Portugal já tinham feito chegar a figuras da Democracia Cristã europeia e italiana, nomeadamente a Fanfani, a quem agradeceram «a viva solidariedade demonstrada por ocasião da injusta medida» e pediram uma intervenção junto das autoridades portuguesas ${ }^{46}$.

\footnotetext{
${ }^{43}$ Cit. por BIANCHI, Luigi, ibidem, capa - p. 2.

${ }^{44}$ DAPAS, Romano - «La questione portoghese». Il Messaggero. Ano 97, N. 78 (23 Mar. 1975) p. 2.

${ }^{45}$ "Chiesto un dibattito sui fatti portoghesi». La Stampa. Ano 109, N. ${ }^{6} 65$ (21 Mar. 1975) p. 2.

${ }^{46}$ VALLI, Bernardo - «Le elezioni portoghesi rinviate al 25 aprile». Corriere della Sera. Ano 100, N. ${ }^{\circ} 65$ (20 Mar. 1975) capa.
} 
Dois dias depois, a 22 de Março, o senador Giuseppe Bartolomei assinava, em nome do grupo da DC, outra petição para discutir os últimos desenvolvimentos, desta vez no Senado. A maioria das facçôes DC foi unânime nos repúdios veiculados. Para Lorenzo Natali ${ }^{47}$, "os factos de Lisboa provaram a estridente contradição entre a proposta do compromisso histórico enquanto expressão de uma linha autónoma e a incapacidade do PCI em libertar-se das raízes de um internacionalismo acrítico».

Porém, ganhavam consistência as reservas dos sectores mais à esquerda da DC. O líder da corrente «Base», Luigi Granelli ${ }^{48}$, vincou a sua discordância: «A involução autoritária em Portugal não impede de observar que um confronto severo com o PCI [...] é em qualquer caso preferível que uma instrumentalização propagandística dos factos condenados, apelando à razáo em detrimento da emotividade».

Também seguindo o propósito da instrumentalização política e eleitoralista, o socialista Giuseppe Di Vagno ${ }^{49}$ considerava que a resposta dos dirigentes da DC tinha sido a «pior possível», tratando-se de «uma grave recusa em querer aprofundar, em termos construtivos e de alargamento dos espaços democráticos, problemas reais».

As tomadas de posição assumiram um carácter frenético e estenderam-se a todos os quadrantes políticos: por exemplo, entre outros, o ex-Presidente da República, Giuseppe Saragat ${ }^{50}$, referiu que «Portugal passou de uma ditadura a outra»; Bettino Craxi (PSI): «Os comunistas são uma flor do estalinismo, um partido que não hesitou em aprovar a intervenção soviética na Checoslováquia»; federação sindical CGIL-CISL-UIL: «Estão em discussão alguns princípios fundamentais e irrenunciáveis para qualquer sistema democrático».

Os enviados dos três jornais em Portugal já tinham previsto que o despacho do CR iria causar réplicas internacionais: Le Monde ${ }^{51}$ - «Os militares satisfeitos por eliminar o PDC não pensaram que uma medida intermédia poderia ser suficiente?»; Frankfurter Allgemeine - «Apesar dos obstáculos, se as eleiçôes forem suficientemente livres realizar-se-á uma considerável maioria náo comunista»; Newsweek ${ }^{52}$ - «Portugal está perdido para a NATO».

Efectivamente, as repercussôes reflectiram o impacto gerado na política interna italiana. Corriere della Sera, La Stampa e Il Messaggero fizeram eco dessas reacçóes. Sobre a verdadeira natureza do PDC em Portugal, ao qual logo a DC italiana se identificou, justificando o retiro do congresso comunista, o líder da DC espanhola José Maria Gil Robles ${ }^{53}$ declarou que o partido português náo fazia parte da União Europeia das Democracias Cristãs. Mas especificou que aquele organismo tinha «adiado a decisão sobre o pedido de adesão para uma fase posterior às eleições». A integração tinha

${ }^{47}$ Cit. por PADELlaro, Antonio - "Chiesto dalla DC un dibattito sul Portogallo», ibidem, N. ${ }^{\circ} 66$ (21 Mar. 1975) capa.

${ }^{48}$ Idem, "Sul ritiro dal congresso comunista», art. cit., ibidem, N. ${ }^{\circ} 68$ (23 Mar. 1975) p. 2.

${ }^{49}$ "Colombo mette in guardia sui pericoli di una rottura", ibidem, N.o 69 (24 Mar. 1975) p. 2.

${ }^{50}$ Cit. por PADELLARO, Antonio - «Chiesto dalla DC...», capa-p. 2.

${ }^{51}$ Cit. por Il Messaggero. Ano 97, N. 76 (21 Mar. 1975) p. 18.

52 «Il Portogallo è perduto perl a NATO», cit. por Corriere della Sera. Ano 100, N.o 69 (25 Mar. 1975) p. 2.

53 "Per i fatti del Portogallo dibattito in Parlamento», cit. por La Stampa. Ano 109, N. 67 (23 Mar. 1975) p. 2. 
sido solicitada pelos dois partidos democratas-cristãos portugueses. Robles condenou ainda a decisão dos militares e negou ter expresso «juízos negativos sobre o partido de Sanches Osório».

No mesmo dia em que o Osservatore Romano ${ }^{54}$ sublinhava «a incapacidade do PCI em condenar uma incrível decisão», o France-Soir dedicava um longo comentário ao impacto produzido na esquerda europeia. «Um PC que embaraça os seus irmãos», assim definia o jornal francês a acção do PCP, avançando que, além da França, a Itália e a Espanha estavam "particularmente interessados no brutal aceleramento do processo revolucionário em Lisboa». E afirmava: «Cunhal mete o PCI em dificuldades».

\section{7. "Um delegado português suscita embaraço no PCI»}

Estão longe de constituírem um parêntese as intervençóes de Aldo Tortorella e Allessandro Natta. Pelo contrário. A intensidade do sismo lusitano foi absorvida pelos muitos delegados que, previamente, pretendiam expressar a opiniẫo. E, quando se fez sentir, requereu destreza para superar o grau de imprevisibilidade. Tal como assevera o cronista da Stampa $a^{55}$ : Ninguém tinha intervençóes preparadas sobre a decisão do governo militar de Lisboa. Mesmo o chefe da delegação soviética, Kirilenko, renovou a solidariedade aos combatentes pela restauraçáo e o desenvolvimento da democracia em Portugal e na Grécia».

Os proeminentes líderes comunistas italianos - e não só - foram obrigados a comentar o alvoroço que os factos de Lisboa tinham causado. Ingrao ${ }^{56}$ expressou «reservas sobre determinadas decisóes da Junta Militar»; Dario Valori mostrou-se preocupado quanto ao peso do Conselho da Revoluçáo no futuro do país; Ferruccio Parri ${ }^{57}$ falou em «especulação fanfaniana»; Paolo Bufalini citou a frase que o emblemático Santiago Carillo proferira momentos antes da sua intervenção: «Não proibiremos [em Espanha] nenhuma força política, grupo ou personalidade que deseje participar na vitória democrática».

$\mathrm{Na}$ verdade, a falta de firmeza revelada inicialmente por Natta e Tortorella em distanciar o PCI da decisão dos militares e, implicitamente, do PCP, que apoiara a medida, causou embaraço e foi criticada pelos observadores. Vários expoentes comunistas admitiram que a resposta não tinha sido suficiente. Outros disseram que foi estratégica.

Só, no final, Berlinguer ${ }^{58}$ desfez, oficialmente, as dúvidas. Afirmou que existia «qualquer coisa nos acontecimentos portugueses» que não persuadia os comunistas italianos, considerando «imperiosos os princípios que envolvem a necessidade de assegurar o pleno exercício de todas as forças políticas de centro, direita ou esquerda, e a todos os cidadãos».

\footnotetext{
54 "Chiesto un dibattito sul Portogallo», cit. por Corriere della Sera. Ano 100, N. 66 (21 Mar. 1975) p. 2.

55 "Portogallo e Italia», capa.

${ }^{56}$ Cit. por DAPAS, Romano - «Nuove voci nel dibattito sul compromesso» Il Messaggero. Ano 97, N. 77 (22 Mar. 1975) p. 2.

${ }^{57}$ Cit. por GIURATO, Luca - «Discorso di Amendola». La Stampa. Ano 109, N.o 64 (20 Mar. 1975) p. 2.

${ }^{58}$ Cit. por DAPAS, Romano - «Dura polemica contro Fanfani». Il Messaggero. Ano 97, N. 79 (24 Mar. 1975) p. 2.
} 
As declarações do secretário-geral fizeram eco em Lisboa e motivaram, sem espera, a reacção do camarada Aurélio dos Santos ${ }^{59}$ (PCP): «Temos bastantes problemas com a nossa situaçáo, aqui em Portugal, para nos ocuparmos com a política italiana. Parece-nos que o princípio a adoptar seja o da não ingerência nas questóes dos outros partidos».

Mas, certamente, as reservas de Berlinguer ganharam verdadeira consistência quando ouviu, no último dia, a frase de Domingos Abrantes ${ }^{60}$, o delegado do PCP presente em Roma: "As ligaçóes fraternas que unem os nossos dois partidos são indestrutíveis». O enunciado foi depressa explorado pela imprensa, considerando Abrantes o orador mais interessante, o hóspede embaraçante, a figura mais esperada.

O grande entusiasmo com que a plateia assistiu ao discurso foi interpretado, pelo Corriere e La Stampa, como uma espécie de contraste latente entre as bases do PCI e a estratégia do compromisso. Por 15 minutos, Abrantes foi aplaudido em 13 ocasiôes, colhendo um forte abraço de Kirilenko. La Stampa dedicou-lhe um título em primeira página: «Um delegado português suscita embaraço no PCI».

O enviado de Álvaro Cunhal, que já tinha concedido uma entrevista ao Corriere della Sera, e mantido reuniōes privadas com Berlinguer, atacou o PDC pelos envolvimentos em acçôes reaccionárias (28 de Setembro e 11 de Março), classificando-o «um partido sem tradiçôes antifascistas». Realçou a "estreita ligação entre o povo e os militares", factor decisivo para a "consolidação democrática», e defendeu um Portugal com as mais amplas liberdades, de imprensa, expressão, reunião, sempre dentro do "pleno respeito pelas conquistas democráticas».

Em que medida a exclusão do Partido da Democracia Cristã das eleiçôes para a Assembleia Constituinte influenciou os trabalhos do XIV Congresso do PCI?

«Enquanto se representava o espectáculo bem ordenado dos oradores, [...] nos bastidores discutia-se o verdadeiro tema do congresso: a exclusão da DC portuguesa das eleiçôes e o clamoroso retiro da delegação da DC italiana». Não queremos ser tão taxativos como Giovanni Russo ${ }^{61}$, do Corriere della Sera. A noção de importância comporta uma elevada carga de subjectividade em jornalismo. Mas é indiscutível que a temática do compromisso histórico partilhou os espaços de debate com os acontecimentos portugueses e, em determinados momentos, cedeu mesmo o brilho ao intruso inesperado.

Porquê? A secretaria de Amintore Fanfani redimensionou a peculiar realidade portuguesa. Inseriu-a noutro contexto através de imbricadas disputas políticas. Construiu uma representação de um dado concreto e introduziu-lhe uma nova carga simbólica. Os motivos - sensatos, discutíveis ou imprudentes - que determinaram a interdição do PDC impossibilitam uma leitura a partir de outros referentes que não os da sociedade portuguesa.

\footnotetext{
${ }^{59}$ Cit. por VIOLA, Sandro - «Nel Portogallo prevale la línea dei piú radicali?». La Stampa. Ano 109, N. ${ }^{\circ} 68$ (25 Mar. 1975) capa.

${ }^{60}$ Cit. por GIURATO, Luca - «Un delegato portoghese suscita imbarazzo nel pci», ibidem, N. 67 (23 Mar. 1975) capa.

${ }^{61}$ RUSSO, Giovanni - «Il delegato comunista portoghese spiega perché la DC è stata messa al bando». Corriere della Sera. Ano 100, N. 66 (21 Mar. 1975) capa.
} 
A instrumentalização dos factos de Lisboa permitiu ao PCI três níveis de actuação. Primeiro: criou uma oportunidade, a partir de um exemplo concreto, de reforçar a proclamada autonomia do discurso introdutório de Berlinguer, a via nacional para o socialismo. Ao criticar a decisão dos militares portugueses demonstrou que a fraternidade entre partidos irmãos não implicava as mesmas condutas.

Segundo: possibilitou uma clara definição em termos estratégicos e de alianças. Se, na antecâmara do congresso, Enrico Berlinguer ainda preconizava uma união de esforços com a secretaria de il professore, depressa percebeu essa impossibilidade. Novo objectivo: derrotar a linha de Fanfani. Náo sem um profundo sentimento de desilusão, como o próprio Berlinguer deixou transparecer na intervenção de encerramento. O gesto de Fanfani provocou o que Soromenho-Marques ${ }^{62}$ designa por hostilidade funcional, "modalidade de apreciação negativa do Outro motivada pela emergência conjuntural de focos de atrito».

Terceiro: tornou evidente a impossibilidade de um compromisso em tempos breves, incorporando assim os desígnios de tempos longos. Talvez o ponto que mais discórdia suscitou entre os históricos do partido durante o debate. Esta imposição decorre da acção fracturante da DC, que se transformou num gigantesco obstáculo à aliança imediata.

Depois, a questáo portuguesa lançou ruído sobre o tema central que deveria ocupar a atenção da opiniấo pública italiana. Comportou, sobre este ponto de vista, um efeito negativo.

«Nem sempre um episódio numa capital estrangeira nos dá o direito de fugir à realidade. [...] Os nossos problemas resolvem-se em Roma e noutras cidades, náo ignorando a política estrangeira, elemento útil de avaliação, mas não aceitando e náo nos iludindo que essa possa ser uma alternativa aos objectivos e às responsabilidades da política interna", observava o editorial do Corriere della Sera ${ }^{63}$.

\section{Qual o tratamento jornalístico concedido à conferência?}

Foram três as principais temáticas enfatizadas pelo Corrriere della Sera, La Stampa e Il Messaggero, durante o XIV Congresso do PCI: o debate em redor do timing do compromisso histórico; a exclusão do PDC das eleiçóes para a Assembleia Constituinte; e o retiro da delegação democrata-cristã do evento comunista.

Quando se tratou de elaborar o intelecto final, os três quotidianos enquadraram o projecto de Berlinguer nos tempos longos, tal como foi referenciado no documento conclusivo do congresso. Mas com enfoques díspares. Corriere della Sera ${ }^{64}:$ «erlinguer

\footnotetext{
${ }^{62}$ SOROMENHO-MARQUES, Viriato - "Antiamericanismo», ob. cit.. In MARUJO, António; FRANCO, José Eduardo - Dança dos demónios. Intolerância em Portugal. Rio de Mouro: Temas e Debates, 2009. ISBN 9789896440725, p. 590.

${ }^{63}$ "Non dimentichiamo i nostri vecchi Mali». Corriere della Sera. Ano 100, N.o 66 (21 Mar. 1975) capa.

${ }^{64}$ BIANCHI, Luigi - «Berlinguer insiste sul compromesso storico e attacca duramente la politica di Fanfani», ibidem. Ano 14, N.o 12 (24 Mar. 1975) capa.
} 
insiste no compromisso histórico». La Stampa ${ }^{65}$ : «Impossível a grande aliança». Il Messaggero ${ }^{66}:$ "Berlinguer contra medidas anti-DC portuguesa».

$\mathrm{Na}$ verdade, os títulos reflectem a linha política das publicaçóes. Piero Ottone assumiu a direcção do colosso milanês, em 1972, e conferiu-lhe uma marca de independência. Retirou-lhe o estigma de hostilidade ao PCI e colocou-o um pouco à esquerda. Ottone defendia um governo de saúde pública.

La Stampa sempre conservou a matriz liberal, mas os reflexos da profunda crise italiana motivaram-lhe, igualmente, um sentimento de adesão a um governo de salvação nacional. Mesmo que, nesta altura, não seja tão declarado. A abertura foi progressiva. Esta consciência era, aliás, cultivada por alguns grandes industrias.

No diário romano reflecte-se, declaradamente, a orientação favorável por uma política de esquerda, acentuada pela radicalidade do corpo redactorial. Por isso, o ténue afloramento da questáo dos tempos longos. O jornal destacou sempre a pertinência do compromisso histórico e a inevitabilidade do PCI, responsável, co-assumir a condução dos destinos do país para sair da profunda crise. Il Messaggero apresentou mesmo uma sondagem em que $32 \%$ dos inquiridos inseriam-se na categoria do provavelmente compromisso histórico em 1976.

A instrumentalização realizada pela secretaria de Fanfani foi reportada como tal pelos meios analisados. Corriere e Stampa consideraram que o PCI tardou em condenar a decisão do CR e distanciar-se do PCP, mas reconheceram que o líder comunista foi mais explícito na intervenção final. Este foi o aspecto mais evidenciado pelo Messaggero, preocupado em sublinhar a autonomia do PCI e a perfeita integraçáo no sistema democrático. E nunca enjeitando a possibilidade de desmistificar o comportamento da DC.

Os dois diários mais difusos de Itália aprofundaram ainda a ambiguidade programática do compromisso histórico, a permanência do PCI na Aliança Atlântica e a opção por uma política mais acutilante nos centros regionais e locais. Estes dois últimos factores mereceram uma apreciação positiva.

Enrico Berlinguer e Amintore Fanfani assumiram o papel nuclear no plano das personagens evocadas. Uma outra sub-categoria envolve os actores episódicos: Giorgio Amendola, Pietro Ingrao, Lugi Longo e Domingos Abrantes. Em termos institucionais, surgiram como referentes incontornáveis o Partido Comunista Italiano, a Democracia Cristá, o Conselho da Revolução e o Partido da Democracia Cristã.

O evento comunista foi abordado numa linguagem dirigida à classe política, de certa forma codificada. Uma das razóes que, no período estudado, explica a baixa difusão da imprensa escrita no país. Expressóes como sacrossanta emoção suscitada pelo drama português ou tragédia de Lisboa revelam um elevado grau de dramatização. Comum na praxis jornalística italiana. Os jornais recolheram variadíssimos testemunhos para sustentar as suas análises e objectivos.

O Corriere (22) foi o jornal que mais unidades de redacção publicou sobre o congresso, seguindo-se o Messaggero (19) e a Stampa (16). Foi também o periódico de Ottone (5)

${ }^{65}$ CASALEGNO, Carlo - «Impossibile la "grande alleanza”». La Stampa. Ano 109, N. 68 (25 Mar. 1975) capa.

${ }^{66}$ DAPAS, Romano - «Berlinguer contro le misure anti-dc portoghese». Il Messaggero. Ano 97, N. ${ }^{\circ} 79$ (24 Mar. 1975) capa. 
que mais editoriais assinou, aparecendo depois o diário de Roma (3). No entanto, a Stampa juntou aos dois editoriais publicados outras cinco notas políticas - texto, normalmente, comentado e circunscrito ao assunto mais importante.

Deste panorama inferimos que a cobertura jornalística decorreu com intensidade e recorreu sobremaneira à interpretação política. A natureza do acontecimento assim o exigia. Várias foram ainda as reportagens ou as notícias condimentadas ao sabor de um preciso comentário político. O jornalista nunca se libertará de valores e tendências ideológicas e manifestará sempre essa condição em todas as produçóes e géneros jornalístico. Os factos não falam sozinhos, necessitam de ser interpretados. Mas importa obter um equilíbrio entre a informação e o comentário. O rigor e os objectivos preconizados determinam o grau de parcialidade e a disfunção de conteúdos

À excepçáo do dia 25 Março, no Corriere, sempre as primeiras páginas dos três quotidianos veicularam narrativas sobre a conferência comunista. E por quatro ocasióes fez a manchete do quotidiano lombardo, em três da Stampa e duas do Messaggero. Dados significativos quanto à relevância adquirida. Não raras vezes observámos que o editorial apareceu ligado à manchete, comentando a notícia ou a crónica política, formando um puzzle de artigos. A interpretação antecedeu assim a informação e direccionou a chave de leitura, induzindo o leitor para a tomada de posição do jornal. Este era um procedimento usual no jornalismo italiano, em profundo contraste, por exemplo, com a cultura anglo-saxónica. 